\title{
Teknik Pembesaran Ikan Kerapu Hibrida Cantang (Epinephelus fuscoguttatus $\times$ Epinephelus lanceolatus) pada Karamba Jaring Apung
}

\author{
Alfian Nur Rochmad ${ }^{1}$, Akhmad Taufiq Mukti $^{2^{*}}$ \\ ${ }^{1}$ Program Studi Akuakultur, Fakultas Perikanan dan Kelautan, Universitas Airlangga; Kampus \\ C Unair, Jl. Mulyorejo, Surabaya, Indonesia 60115, (031) 5911451 \\ ${ }^{2}$ Departemen Manajemen Kesehatan Ikan dan Budidaya Perairan, Fakultas Perikanan dan \\ Kelautan, Universitas Airlangga; Kampus C Unair, Jl. Mulyorejo, Indonesia 60115, (031) \\ 5911451 \\ *e-mail: ${ }^{2}$ akhmad-t-m@fpk.unair.ac.id
}

\begin{abstract}
Abstrak
Ikan kerapu hibrida cantang merupakan komoditas perikanan yang memiliki peluang baik di pasaran karena nilai gizi dan ekonomisnya yang tinggi. Ikan kerapu hibrida ini banyak dibudidayakan di karamba jaring apung laut (KJAL). Permintaan ikan kerapu di pasaran cukup tinggi, sehingga perlu dilakukan kegiatan pembesarannya. Tujuan dari studi ini adalah untuk mengetahui teknik pembesaran, pertumbuhan, serta kendala dalam kegiatan pembesaran ikan kerapu hibrida cantang pada KJAL. Studi ini dilaksanakan di Instalasi Budidaya Laut (IBL) Boncong, Tuban, Jawa Timur. Metode yang digunakan adalah observasi dan mengumpulkan data melalui wawancara serta studi literatur. Hasil studi ini menunjukkan bahwa pemilihan lokasi KJAL harus bebas dari limbah pencemaran, dasar berlumpur, dan dikelilingi terumbu karang. Benih ikan yang ditebar berukuran 9-12 cm dengan padat tebar 500 ekor/unit. Pakan yang diberikan berupa ikan rucah. Panjang total, lebar, dan bobot tubuh ikan diukur setiap seminggu sekali. Berdasarkan hasil study menunjukkan bahwa panjang, lebar dan bobot tubuh ikan kerapu hibrida cantang meningkat setiap minggunya selama masa pembesaran. Kendala dalam pembesaran ikan kerapu di KJAL adalah ketersediaan ikan rucah sebagai pakan dan gelombang laut yang tidak menentu.
\end{abstract}

Kata kunci : ikan kerapu hibrida cantang, masa pembesaran, karamba jaring apung laut

\begin{abstract}
Cantang hybrid grouper fish is a fishery commodity that has a good opportunity in the market because of its high nutritional and economic value. This hybrid grouper fish began to be widely cultivated in the sea floating net cages (SFNC). Demand for grouper fish on the market is quite high so it is necessary to fish grow-out. The aim of this studywas known growout techniques and the constraints in the grow-out of the cantang hybrid grouper fish at the SFNC. This study was conducted at the Mariculture Installation, Boncong, Tuban, East Java. Methods used were observation and collection of data through interviews and literature study. Selection of the SFNC must be free from pollution, muddy bases, and surrounded by coral reefs. The stocked seeds are 9-12 cm in size at a density of 500 fish/unit of the SFNC. The fish was fed a trash fish. The total length, width, and body weight of groupers were measured every weeks. Based on the study indicated that total length, width, and body weight of cantang hybrid grouper fish have increased every weeks during grow-out period. The obstacles in this grow-out of grouper fish at the SFNC are the availability of trash fish as feed stock and erratic sea wave.
\end{abstract}

Keywords : cantang hybrid grouper fish, grow-out period, sea floating net cage 


\section{PENDAHULUAN}

Ikan kerapu hibrida cantang merupakan komoditas perikanan yang memiliki peluang pasar tinggi, baik di pasar domestik maupun ekspor, karena nilai gizi dan ekonomisnya yang tinggi. Ikan kerapu hibrida cantang (Epinephelus fuscoguttatus $\times$ Epinephelus lanceolatus) adalah ikan hibrida hasil perkawinan silang antara ikan kerapu macan (E. fuscoguttatus) betina dan ikan kerapu kertang (E. lanceolatus) jantan yang telah dikembangkan dengan tujuan untuk memproduksi jenis ikan kerapu baru yang memiliki keunggulan dan dapat dibudidayakan di karamba jaring apung (KJA). Keunggulan ikan kerapu hibrida cantang adalah pertumbuhan yang cepat, kecepatan tumbuhnya dua kali lipat dari ikan kerapu macan yang biasa dibudidayakan masyarakat (Chaniago, 2020).

Ikan kerapu hibrida cantang memiliki bentuk tubuh compress dan relatif membulat dengan ukuran lebar kepala sedikit atau hampir sama dengan lebar badannya, kulit berwarna coklat kehitaman dengan lima garis hitam melintang di bagian tubuhnya, semua sirip bercorak seperti ikan kerapu kertang dengan dasar berwarna kuning yang dilengkapi bintik-bintik hitam yang juga banyak tersebar di kepala dan di dekat sirip pectoral dengan jumlah yang berbeda pada setiap individu, sirip punggung melebar ke arah belakang, menyatu dan terdiri atas 11 jari-jari keras dan 15 jari-jari lunak, sirip pectoral terdiri atas 17 jari-jari lunak, sirip ventral terdiri dari 1 jari-jari keras dan 5 jarijari lunak, sirip anal terdiri dari 2 jari-jari keras dan 8 jari-jari lunak, sedangkan sirip caudal terdiri atas 13 jari-jari lunak, bentuk ekor rounded, bentuk mulut lebar superior (bibir bawah lebih panjang dari bibir atas), tipe sisik ctenoid (bergerigi), dan bentuk gigi runcing (canine). Ikan kerapu hibrida cantang memiliki ciri khas yang membedakan dengan induknya yaitu warna kulit coklat kehitaman dengan lima garis hitam dan memiliki bintik hitam yang tersebar di bagian kepala dan dekat sirip pectoral (Rizkya, 2012), sebagaimana terlihat pada Gambar 1.

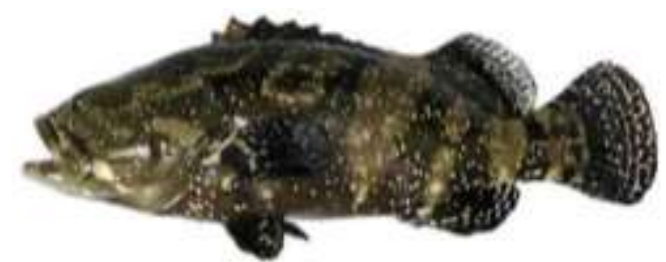

Gambar 1. Ikan kerapu cantang (Rizkya, 2012)

Data BPS (2020) mencatat nilai ekspor ikan kerapu hidup Indonesia periode Januari 2019 sampai dengan Januari 2020 banyak mengalami fluktuatif. Bulan Januari 2019 volume ekspor kerapu hidup di Indonesia mencapai 277.006 ton. Volume ekspor kerapu hidup tertinggi terjadi pada bulan Maret 2019 yang mencapai 317.874 ton dan volume ekspor terendah terjadi pada bulan Agustus 2019 dengan total 99.316 ton. Volume ekspor kerapu semenjak bulan Agustus hingga Desember 2019 mengalami kenaikan tiap bulannya hingga mencapai 205.572 ton di akhir tahun. Data BPS (2020) menunjukkan bahwa pada Januari 2020 volume ekspor kerapu hidup di Indonesia mencapai 165.87 ton atau turun $19.32 \%$ dibandingkan bulan Desember 2019 (205.572 ton). Nilai ekspor kerapu hidup di Indonesia bulan Januari 2020 mencapai USD 1.74 juta atau turun $20.8 \%$ dibandingkan bulan Desember 2019 sebanyak USD 2.20 juta.

Pembesaran adalah salah satu kegiatan pemeliharaan ikan yang bertujuan untuk menghasilkan ikan dengan ukuran konsumsi. KJA merupakan media budidaya ikan yang ideal dan ditempatkan di badan air dalam. Keadaan air yang cukup tinggi serta kualitas lingkungan perairan yang memadai menjadikan KJA alternatif yang baik untuk kegiatan budidaya. Secara umum, KJA terdiri dari komponen seperti rakit, pelampung, pemberat, jangkar, kantong jaring dan gudang. Komponen tersebut akan membentuk satu unit KJA yang saling memperkuat antar satu dengan yang lainnya (Affan, 2011).

Instalasi Budidaya Laut Boncong merupakan salah satu Instalasi yang mengembangkan budidaya ikan kerapu hibrida cantang pada KJAL di Jawa Timur. Mengingat pentingnya pengembangan teknologi pada kegiatan pembesaran ikan kerapu hibrida cantang, maka studi ini dilakukan bertujuan untuk mengetahui 
teknik pembesaran, pertumbuhan, dan kendala dalam kegiatan pembesaran ikan kerapu hibrida cantang di KJAL.

\section{METODE PENELITIAN}

Studi ini ini dilaksanakan di Instalasi Budidaya Laut (IBL) Boncong, Tuban, Jawa Timur pada bulan Desember 2019 sampai dengan Januari 2020. IBL Boncong merupakan satu-satunya instalasi di UPT Pengembangan Budidaya Laut Dinas Kelautan dan Perikanan Provinsi Jawa Timur yang berada di Kabupaten Tuban. IBL Boncong berada di Jl. Raya TubanSemarang km 41-42 Desa Boncong, Kecamatan Bancar, Kabupaten Tuban. Posisi koordinat IBL Boncong berada pada $111^{\circ}$ LS dan $6^{\circ} 30^{\prime}$ BT. Posisi geografis instalasi ini berjarak $145 \mathrm{~km}$ dari ibukota Provinsi Jawa Timur, $45 \mathrm{~km}$ dari kota kabupaten, $5 \mathrm{~km}$ dari kota kecamatan

Metode yang digunakan dalam studi ini adalah metode observasi dengan pengumpulan data primer dan studi literatur sebagai data sekunder. Teknik pembesaran yang dilakukan di KJAL diamati setiap hari, termasuk pemberian pakan ikan selama pembesaran.

Pengukuran kualitas air, seperti suhu, $\mathrm{pH}$, oksigen terlarut (OT) dan salinitas air dilakukan satu minggu sekali. Suhu dan OT diukur menggunakan skala suhu dan OT yang ada di DOmeter. $\mathrm{pH}$ diukur menggunakan pHmeter, sedangkan salinitasdiukur menggunakan refraktometer. Pengukuran panjang dan lebar total serta bobot tubuh ikan kerapu hibrida cantang dilakukan setiap seminggu sekali selama empat minggu. Analisis data dilakukan secara deskriptif.

\section{HASIL DAN PEMBAHASAN}

\section{Pemilihan Lokasi}

Lokasi KJAL yang ada di IBL Boncong berada di Pantai Utara yang terletak $700 \mathrm{~m}$ dari bibir pantai dengan kedalaman $4 \mathrm{~m}$ saat kondisi air pasang dan 2,5 m saat air surut dengan dasar berlumpur. KJAL dikelilingi oleh terumbu karang yang ada di dasar perairan supaya ombak yang datang bisa dipecah. Pemilihan lokasi KJAL yang dilakukan di IBL Boncong ini juga jauh dari limbah pencemaran terutama limbah yang berada di samping balai yaitu limbah pencucian pasir serta jauh dari jalur pelayaran dan aktivitas rumah warga.

Persyaratan lokasi KJAL harus bebas dari faktor resiko seperti gangguan alam (badai dan gelombang besar), adanya predator (hewan buas laut dan burung laut), pencemaran (limbah industri, pertanian dan rumah tangga) dan konflik pengguna (lalulintas kapal umum dan kapal tanker). Persyaratan kondisi hidrografi meliputi kedalaman air lebih dari $5 \mathrm{~m}$, kadar garam 20-35 ppt, oksigen terlarut 3-7 ppm, kecepatan arus $0.1-0.5 \mathrm{~m} /$ detik, tinggi air pasang 0,5-1,5 meter, pH 6-8,5 dan suhu 27$32{ }^{\circ} \mathrm{C}$. Faktor pendukung lainnya yaitu seperti sumber pakan, tenaga kerja dan ketersediaan benih merupakan syarat-syarat yang harus dipenuhi (Zulkifli dkk., 2000).

\section{Tata Letak Keramba Jaring Apung}

Penempatan KJAL sangat penting memperhatikan kondisi perairan laut, terutama arus dan gelombang, hal ini berkaitan dengan sirkulasi air dan ketahanan keramba. Penempatan keramba yang tidak sesuai bisa berakibat fatal. Semua komponen seperti rakit, keramba, pelampung dan jangkar harus disusun dalam satu unit KJAL di lokasi yang terpilih dan sesuai (KKP, 2011).

Penempatan unit keramba yang baik adalah tegak lurus dengan arah arus dan gelombang sehingga semua unit jaring atau keramba memiliki peluang pergantian air yang sama. Bahan pengikat unit keramba supaya tidak bergeser adalah jangkar yang dipasang di dasar perairan. Panjang tali yang digunakan untuk mengikat jangkar dengan kerangka keramba minimal dua kali dari kedalaman air pada saat pasang (KKP, 2011).

\section{Konstruksi KJA}

Rakit berbentuk bujur sangkar dengan ukuran $3 \mathrm{~m} \times 3 \mathrm{~m}$ yang terbuat dari high density polyethylene (HDPE) yang diproduksi oleh Aquatec, Indonesia. Pelampung terbuat dari pipa galvanis yang 
dapat mengapung di perairan. Rakit dan pelampung berfungsi untuk menahan jaring agar tetap terbuka di permukaan air, sedangkan jaring yang tertutup di bagian bawahnya digunakan untuk memelihara ikan selama beberapa bulan (Mahaputra, 2017)

KJAL memiliki jaring yang terbuat dari tali polyethylene (PE) dengan ukuran $3 \mathrm{~m} \times$ $3 \mathrm{~m} \times 3 \mathrm{~m}$. Mata jaring yang digunakan terbagi atas dua ukuran yakni $1,25 \mathrm{~cm}$ dan $2,5 \mathrm{~cm}$. Mata jaring $1,25 \mathrm{~cm}$ digunakan untuk ikan berukuran 9-11 cm, sedangkan mata jaring $2,5 \mathrm{~cm}$ digunakan untuk ikan berukuran $12-15 \mathrm{~cm}$.

KJAL yang digunakan harus memiliki pemberat dan jangkar agar berdiri kokoh dan tidak terbawa oleh arus air. Pemberat terbuat dari besi dengan berat $5 \mathrm{~kg}$ yang dipasang pada tiap sudut jaring berjumlah empat buah. Pemberat berfungsi untuk mempertahankan bentuk jaring agar tetap stabil. Jangkar terbuat dari besi dengan berat $300 \mathrm{~kg}$ berjumlah 12 buah dan diikatkan pada setiap sudut dengan tali PE dengan menghadap arah mata angin.

\section{Seleksi Benih}

Seleksi benih bertujuan untuk mengetahui kondisi benih ikan kerapu hibrida cantang yang sehat, memiliki gerakan yang aktif, berkoloni serta memiliki respon yang baik terhadap pakan, kejutan dan cahaya. Benih ikan kerapu hibrida cantang yang baik memiliki kriteria seperti ukurannya seragam, bebas dari penyakit, warna coklat keabu-abuan, bentuk tubuh sempurna dan anggota tubuh lengkap, gerakan aktif, berenang normal dan bergerombol serta memiliki respon baik terhadap pakan (BSN, 2014). Benih ikan kerapu hibrida cantang yang digunakan dalam kegiatan pembesaran di KJAL didapatkan dari Unit Perikanan Budidaya Laut (UPBL) Situbondo dengan ukuran 2,7$3,5 \mathrm{~cm}$. Benih kemudian dilakukan proses penggelendongan di kolam penggelendongan sampai berukuran 9-12 cm selama 30 hari.

\section{Penebaran Benih}

Benih ditebar pada pagi atau sore hari saat suhu perairan tidak terlalu panas. Panas pada perairan akan mempengaruhi kondisi tubuh dari benih dan sistem metabolismenya. Benih dilakukan proses aklimatisasi terlebih dahulu sebelum ditebar di KJAL. Aklimatisasi dilakukan dengan cara menenggelamkan setengah mulut plastik selama 5-10 menit. Aklimatisasi bertujuan agar ikan tidak stress akibat perbedaan suhu yang fluktuatif dan lingkungan (Faisyal dkk., 2016).

Benih ikan kerapu hibrida cantang yang ditebar pada KJAL memiliki ukuran 9-12 $\mathrm{cm}$. Penebaran dilakukan menggunakan bak persegi yang diberi selang aerasi, kemudian dibawa menggunakan katamaran. Ikan diambil menggunakan serok dan menghitung jumlahnya kemudian dilepas ke petak keramba. Ikan ditebar pada 10 unit KJAL dengan padat tebar sebanyak 500 ekor/unit KJAL. Benih ikan harus memiliki ukuran seragam agar tidak terjadi kanibalisme. WWF-Indonesia (2011) menyatakan bahwa padat tebar benih ikan kerapu maksimal sebanyak 500 ekor pada KJA.

\section{Teknik Pemberian Pakan}

Pakan yang digunakan untuk ikan kerapu hibrida cantang di KJAL adalah ikan rucah yang diperoleh dari pengepul pakan di daerah Bulu, Tuban dengan harga $\mathrm{Rp}$ $5.500,00 / \mathrm{kg}$. Frekuensi pemberian pakan sebanyak sehari sekali. Ikan rucah diberikan dalam keadaan terpotong sesuai dengan bukaan mulut ikan kerapu hibrida cantang. Pakan ikan rucah diberikan dengan tangan secara sedikit demi sedikit sampai ikan terlihat kenyang, hal tersebut sesuai dengan pernyataan Tumadang dkk. (2016) bahwa pemberian pakan dilakukan dengan menebarkan pakan dengan tangan sedikit demi sedikit sampai ikan terlihat kenyang.

\section{Pengamatan Kualitas Air}

Data pengamatan parameter air selama pembesaran ikan kerapu hibrida cantang di KJAL dapat dilihat pada Tabel 1.

Tabel 1. Parameter kualitas air selama pemeliharaan ikan kerapu hibrida cantang di KJAL

\begin{tabular}{|c|c|c|c|c|}
\hline Minggu & $\begin{array}{c}\text { Suhu } \\
\left({ }^{\circ} \mathrm{C}\right)\end{array}$ & $\mathrm{pH}$ & $\begin{array}{c}\text { OT } \\
(\mathrm{ppm})\end{array}$ & $\begin{array}{c}\text { Salinitas } \\
(\mathrm{ppt})\end{array}$ \\
\hline
\end{tabular}




\begin{tabular}{|c|c|c|c|c|}
\hline I & 29,3 & 7,81 & 6,59 & 38 \\
\hline II & 29,0 & 7,84 & 6,34 & 36 \\
\hline III & 29,5 & 7,95 & 6,84 & 36 \\
\hline IV & 26,5 & 7,68 & 6,50 & 35 \\
\hline Ref $^{*}$ & $27-32$ & $7,0-8,5$ & $>4$ & $30-34$ \\
\hline
\end{tabular}

Keterangan: OT $=$ oksigen terlarut, ${ }^{*}$ Firdaus et al. (2016)

Suhu berperan bagi kehidupan dan pertumbuhan ikan kerapu cantang. Data pengukuran suhu yang didapat termasuk kategori baik, karena suhu optimum untuk pembesaran kerapu cantang berkisar 24-31 ${ }^{\circ} \mathrm{C}$ (Yoshimitsu et al., 1986).

Data pengukuran $\mathrm{pH}$ yang didapat termasuk kategori baik, karena kisaran $\mathrm{pH}$ yang baik untuk pembesaran kerapu cantang yaitu 7,0-8,5 (Hendriansyah dkk., 2018). Nilai $\mathrm{pH}$ diatas atau dibawah optimum akan menyebabkan kematian pada ikan, sebab $\mathrm{pH}$ mempengaruhi kondisi perairan yang merupakan media untuk hidup ikan (Hendriansyah dkk., 2018).

Data pengukuran oksigen terlarut yang didapat termasuk kategori baik, karena oksigen terlarut yang baik untuk pembesaran kerapu cantang yaitu lebih dari 3,5 ppm (Yoshimitsu et al., 1986). Oksigen terlarut merupakan konsentrasi gas oksigen yang terlarut dalam air dan merupakan salah satu faktor yang penting dalam kehidupan organisme untuk respirasi (Marpaung dkk., 2018).

Salinitas memiliki peranan penting yaitu untuk meningkatkan kelangsungan hidup dan metabolisme ikan. Data pengukuran salinitas yang didapat termasuk kategori kurang baik, karena salinitas yang baik untuk pembesaran kerapu cantang yaitu 30-33 ppt (Hendriansyah dkk., 2018).

\section{Perawatan KJA}

Perawatan KJAL dilakukan selama satu bulan sekali dengan bantuan kurang lebih 6 orang. Perawatan berupa mencuci jaring atau membersihkan jaring dari teritip dan kerang hijau yang menempel menggunakan susuk, jaring yang lubang dijahit kembali menggunakan "coban" dan benang nilon.

\section{Pengamatan Panjang, Lebar dan Bobot Tubuh Ikan Selama Pembesaran}

Pengamatan panjang, lebar dan bobot tubuh ikan kerapu hibrida cantang dilakukan dengan cara sampling sebanyak sepuluh ekor secara acak, sebagaimana terlihat pada Tabel 2.

Tabel 2. Data panjang, lebar dan bobot tubuh ikan kerapu hibrida cantang selama pembesaran di KJAL

\begin{tabular}{|c|c|c|c|c|}
\hline & $\begin{array}{c}\text { Minggu } \\
\text { I }\end{array}$ & $\begin{array}{c}\text { Minggu } \\
\text { II }\end{array}$ & $\begin{array}{c}\text { Minggu } \\
\text { III }\end{array}$ & $\begin{array}{c}\text { Minggu } \\
\text { IV }\end{array}$ \\
\hline $\begin{array}{c}\text { PTt } \\
(\mathrm{cm})\end{array}$ & 276,5 & 296,5 & 316,5 & 333,9 \\
\hline $\begin{array}{c}\text { PTr } \\
(\mathrm{cm})\end{array}$ & 27,65 & 29,65 & 31,65 & 30,39 \\
\hline $\begin{array}{c}\mathrm{LTt} \\
(\mathrm{cm})\end{array}$ & 83,3 & 100,5 & 124,5 & 164,4 \\
\hline $\begin{array}{c}\mathrm{LTr} \\
(\mathrm{cm})\end{array}$ & 8,33 & 10,05 & 12,45 & 16,44 \\
\hline $\begin{array}{c}\mathrm{BTt} \\
(\mathrm{g})\end{array}$ & 4159 & 5804 & 6544 & 9900 \\
\hline $\begin{array}{c}\mathrm{BTr} \\
(\mathrm{g})\end{array}$ & 415,9 & 580,4 & 654,4 & 990 \\
\hline
\end{tabular}

Keterangan:PTt $=$ Panjang tubuh total, $\mathrm{PTr}=$ Panjang tubuh rerata, $\mathrm{LTt}=$ Lebar tubuh total, $\mathrm{LTr}=$ Lebar tubuh rerata, $\mathrm{BTt}=$ Bobot tubuh total, $\mathrm{BTr}=$ bobot tubuh rerata

Berdasarkan data pada Tabel 2 menunjukkan bahwa ikan kerapu hibrida cantang mengalami pertumbuhan pada minggu pertama hingga minggu keempat. Pertumbuhan ikan kerapu hibrida cantang ditunjukkan dengan adanya pertambahan panjang, lebar dan bobot tubuh ikan. Pertambahan panjang, lebar dan bobot tubuh ikan kerapu hibrida cantang terlihat lebih tinggi setelah minggu ketiga pembesaran di KJAL.

\section{Penanganan Hama dan Penyakit}

Hama yang sering menyerang ikan kerapu hibrida cantang di KJAL adalah teritip, kerang hijau dan kepiting. Teritip dan kerang hijau dapat menyebabkan jaring berlubang serta menghambat sirkulasi air pada jaring. Teritip memiliki cangkang yang tajam sehingga apabila teritip menempel pada jaring maka akan melukai ikan kerapu hibrida cantang yang dipelihara (Noor dkk., 2018). Penanganan terhadap hama teritip dan kerang hijau dilakukan dengan 
membersihkan jaring menggunakan susuk, sedangkan jaring yang berlubang dijahit kembali menggunakan "coban" dan benang seperti nilon. Hama lain yang mengganggu budidaya ikan kerapu hibrida cantang di KJAL adalah kepiting. Pencegahannya harus sering dilakukan pengontrolan secara rutin (Alit dkk., 2014).

Penyakit yang ditemukan adalah parasit kutu air atau Isopoda dan lintah laut. Isopoda ditemukan pada sirip dorsal dari ikan kerapu hibrida cantang. Penanganan untuk ikan terinfeksi parasit ini dapat dilakukan dengan cara perendaman menggunakan air tawar selama 10-15 menit. Direktorat Jenderal Perikanan Budidaya (2017) juga mengatakan bahwa penanganan ikan terinfeksi parasit air laut yaitu dengan perendaman air tawar atau dengan salinitas 5 ppt selama 10-15 menit atau $\mathrm{H}_{2} \mathrm{O}_{2} 150$ ppm selama 30 menit

Lintah laut yang ditemukan merupakan genus dari Zeylanicobdella yang banyak menyerang pada bagian permukaan tubuh ikan kerapu hibrida cantang. Penanganan penyakit pada ikan di IBL Boncong biasanya melalui perendaman dalam formalin atau air tawar. Perendaman dalam air tawar dilakukan selama 5-10 menit kemudian disemprot dengan air laut, sedangkan perendaman dalam formalin dengan konsentrasi 100 ppm selama kurang lebih 5 menit. Singkat atau lamanya waktu perendaman tergantung dari banyaknya dosis yang digunakan. Semakin tinggi dosisnya, maka semakin cepat waktu perendaman dengan formalin.

Perlakuan terhadap lintah ini bisa dilakukan dengan perendaman dalam formalin 200-250 ppm selama 1 jam. Pemakaian formalin dengan konsentrasi tinggi dapat mengganggu pernafasan ikan, oleh karena itu diperlukan aerasi yang kuat dalam perlakuan tersebut. Namun, penggunaan air tawar dipandang lebih aman karena perlakuan dilakukan hampir 5-7 hari sekali. Perendaman pun dilakukan hanya sebentar (kurang dari setengah jam) diikuti dengan pengurutan tubuh ikan dengan tangan untuk membantu melepaskan lintah (Mahardika dkk., 2018).

\section{Analisis Usaha}

Panen pada budidaya ikan kerapu hibrida cantang di KJAL umumnya dilakukan setelah enam bulan pemeliharaan dengan bobot tubuh ikan rerata mencapai 400-600 g/ekor.

Analisis usaha adalah suatu upaya yang dilakukan untuk mengetahui sejauh mana kegiatan usaha mengalami keuntungan atau tidak, serta mengukur keberlanjutan usaha tersebut (Ramadhi, 2014). Komponen biaya dalam analisis usaha terdapat biaya inventasi sebesar Rp.133.570.000,-, biaya tetap sebesar Rp. 33.800.000,-, biaya variabel sebesar Rp. 64.950.000,-, dan biaya total sebesar Rp. 98.750.000,-.

Keuntungan dalam kegiatan pembesaran ikan kerapu hibrida cantang pada KJAL di IBL Boncong, Tuban ini menghasilkan laba sebesar Rp 6.083.900,per tahun. Rasio R/C dari kegiatan pembesaran ikan kerapu hibrida cantang ini sebesar 1,06, artinya nilai R/C lebih besar dari satu, dengan demikian usaha pembesaran ikan kerapu hibrida cantang ini layak untuk dijalankan atau dikembangkan.

Break event point (BEP) yang dihasilkan sebesar $1161,76 \mathrm{~kg}$ per tahun dan $B E P$ harga sebesar Rp. 80.067,- per kg, artinya pengembalian modal kegiatan pembesaran ikan kerapu hibrida cantang di KJAL dapat dilakukan dalam satu tahun melalui penjualan hasil panen sebesar $1161,76 \mathrm{~kg}$ per tahun dengan harga $\mathrm{Rp}$. 80.067 ,- per $\mathrm{kg}$. Hasil perhitungan payback periode $(P P)$ adalah 1,2 tahun, artinya pengembalian biaya yang dikeluarkan dalam pembesaran ikan kerapu hibrida cantang di KJAL membutuhkan waktu sekitar 1,2 tahun.

\section{KESIMPULAN DAN SARAN}

Teknik pembesaran ikan kerapu hibrida cantang pada KJAL meliputi pemilihan lokasi KJAL, tata letak dan konstruksi KJAL, seleksi benih, penebaran benih, teknik pemberian pakan, pengamatan kualitas air, perawatan KJAL, pengamatan pertumbuhan dan pengendalian hama dan penyakit. Permasalahan yang timbul selama kegiatan pembesaran ikan kerapu hibrida 
cantang di KJAL antara lain cuaca buruk, angin kencang, gelombang besar, arus yang deras serta adanya hama dan penyakit yang disebabkan oleh kutu air dan lintah laut. Diharapkan ketersediaan pakan ikan rucah untuk ikan harus selalu terpenuhi tepat waktu agar kebutuhan pakan pada ikan dapat tercukupi dengan baik. Kegiatan monitoring terhadap kondisi lingkungan juga perlu dilakukan secara teratur seperti pengontrolan kondisi ikan kerapu cantang yang dibudidayakan, pengecekan kualitas air, pembersihan jaring dan pemeriksaan terhadap kerusakan jaring.

\section{UCAPAN TERIMA KASIH}

Penulis mengucapkan terima kasih kepada Kepala dan staf Instalasi Budidaya Laut (IBL) Boncong Tuban yang telah memberikan dukungan dan bantuan penyediaan sarana dan prasarana serta pengambilan data.

\section{DAFTAR PUSTAKA}

Affan, J. M. 2011. Seleksi Lokasi Pengembangan Budidaya Dalam Keramba Jaring Apung (KJA) Berdasarkan Faktor Lingkungan dan Kualitas Air di Perairan Pantai Timur Kabupaten Bangka Tengah. Jurnal Sains MIPA, 17 (3): 99-106.

Alit, A. A., K. M. Setiawan dan T. S. Dharma. 2014. Teknik Pendederan Benih Ikan Kerapu Sunu Plectropomus leopardus dengan Jenis Pakan Berbeda. Jurnal Ilmu dan Teknologi Kelautan Tropis, 6 (2): 373-381.

Badan Pusat Statistik. 2020. Nilai Ekspor Kerapu Hidup Indonesia. www.bps.go.id. Diakses tanggal 26 April 2020.

Badan Standardisasi Nasional (BSN). 2014. Ikan Kerapu Cantang (Epinephelus fuscoguttatus, Forsskal $1775 \times$ Epinephelus lanceolatus, Bloch 1790) Bagian 1: Benih Hibrida. Jakarta. Hal. 5-6.

Chaniago, A. A. 2020. Hibridisasi Ikan Kerapu Macan (Epinephelus fuscoguttatus) dan Ikan Kerapu Kertang (Epinephelus lanceolatus). Makalah
Ilmiah. Fakultas Ilmu Kelautan dan Perikanan. Universitas Maritim Raja Ali Haji. Riau. Hal. 3.

Direktorat Jenderal Perikanan Budidaya. 2017. Penanganan Penyakit pada Usaha Budidaya Ikan Laut. Balai Besar Perikanan Budidaya Laut Lampung. Lampung. Hal. 4.

Faisyal, Y., S. Rejeki dan L. L. Widowati. 2016. Pengaruh Padat Tebar Terhadap Pertumbuhan dan Kelulushidupan Ikan Bandeng (Chanos chanos) di Keramba Jaring Apung di Perairan Terabrasi Desa Kaliwlingi Kabupaten Brebes. Journal of Aquaculture Management and Technology, 5 (1): 155- 161.

Firdaus, R. F., Lim, L. S., Kawamura, G. and Shapawi, R. 2016. Assessment on the Acceptability of Hybrid Grouper, Epinephelus fuscoguttatus $q \times$ Epinephelus lanceolatus $\widehat{\partial}$ to Soybean meal-based Diets. AACL Bioflux, 9 (2): 284-290.

Eendriansyah, A., W. K. A. Putra dan S.Miranti. 2018. Rasio Konversi Pakan Benih Ikan Kerapu Cantang (Epinephelus fuscoguttatus $\mathrm{x}$ Epinephelus lanceolatus) dengan Pemberian Dosis recombinant Growth Hormone ( $\mathrm{rGH})$ yang Berbeda. Jurnal Intek Akuakultur, 2 (2): 1-12.

KKP Dirjen Perikanan Budidaya. 2011. Profil Ikan Kerapu Indonesia. Direktorat Produksi. Jakarta. 133 Hal.

Mahaputra, G. M. 2017. Penentuan Lokasi Budidaya Keramba Jaring Apung di Perairan Teluk Prigi Kabupaten Trenggalek Dengan Pendekatan Sistem Informasi Geografis. Tugas Akhir. Fakultas Tekonologi Kelautan. Institut Teknologi Sepuluh Nopember Surabaya. 84 Hal.

Mahardika, K., I. Mastuti dan Zafran. 2018. Respon Lintah Laut (Zeylanicobdella arugamensis) Terhadap Salinitas Berbeda Secara Laboratorium. Journal of Fisheries and Marine Research, 2 (3): 208-214.

Marpaung, L. S., Y. Wardiatno., I. Setyobudiandi dan T. Arifin. 2018. Daya Dukung Budidaya Ikan Kerapu Pada Keramba Jaring Apung Teluk Awang dan Teluk Bumbang, NTB. Jurnal Teknologi Perikanan dan 
Jurnal Biosains Pascasarjana Vol. 22 (2020) pp

(C) (2020) Sekolah Pascasarjana Universitas Airlangga, Indonesia

Kelautan, 9 (1): 43-53.

Noor, S. Y., Y. Adipu dan N. Auliyah. 2018. Pendampingan Budidaya Kerapu Tikus pada Kelompok Bahtera Lamu dan Lamu Bahari di Desa Lamu Kabupaten Bualemo. Jurnal Panrita Abdi, 2 (1) : 33-39.

Ramadhi, J. 2014. Analisis Usaha Pedagang Ikan pada Pasar Ikan di Kecamatan Seunagan Kabupaten Nagan Raya. Skripsi. Fakultas Perikanan dan Ilmu Kelautan. Universitas Teuku Umar. Meulaboh. 36 hal.

Rizkya, M. 2012. Pembenihan Ikan Kerapu Cantang (Epinephelus Sp.) di Balai Perikanan Budidaya Air Payau (BPBAP) Situbondo-Jawa Timur. Sekolah Tinggi Perikanan. Bogor. 42 Hal.

Tumadang, L. S. N., J. Sampekalo dan S. Lantu. 2016. Pengaruh Pemberian Beberapa Jenis Pakan Pada Pertumbuhan Ikan Kerapu Cantang Epinephelus Sp. di Karamba Jaring Apung di Teluk Talengen Kepulauan Sangihe. Jurnal Budidaya Perairan, 4 (3): $1-9$.

WWF-Indonesia. 2011. Budidaya Ikan Kerapu Sistem Keramba Jaring Apung dan Tancap. Jakarta. Hal. 12.

Yoshimitsu, T., H. Eda and K. Hiramatsu. 1986. Groupers Final Report Marineculture Research and Development in Indonesia. ATA 192, JICA: 103-129.

Zulkifli, M. N., T. Iskandar, Mukhlisuddin, A. Azis, Yulham, Bahrum, C. Nina, Amir, Baharuddin dan Zuardi. 2000. Rakitan Teknologi Budidaya Kerapu Dalam Keramba Jaring Apung (KJA). Jurnal Penelitian Budidaya Pantai, 1 (5): 51-60. 